\title{
Fact Checking Is Needed in Science Also
}

\author{
Henry H. Bauer
}

Fact checking of political statements has become a prominent topic in the mass media in recent years, a consequence of improved technology, the proliferation of news sources, and increased political polarization. Assertions by political figures are routinely compared with or contrasted to "science" or to "facts," as though science and facts were identical. But facts are expected to be observable fairly directly, without intervention of sophisticated instrumentation or expert interpretation, whereas science is what the scientific community happens to disseminate. Those are by no means always the same thing. Therefore, when scientific advice is offered to policymakers on matters of public importance, a strong case can be made for fact-checking that advice against primary sources of empirical facts.

An overriding reason for this careful diligence is the insight shared by historian Lorraine Daston: the dilemma of "whether scientific progress ... [is] compatible with scientific truth." ${ }^{1}$ Scientific understanding, the scientific consensus, changes over time; yet the status, prestige, and authority of science rests on the belief that what science says can be relied upon at any given time to be true rather than misleading or mistaken.

Yet any contemporary scientific advice reflects only a consensus that is fallible because it is possibly temporary; but that fallibility is not usually emphasized to policymakers; it may not even be recognized by those offering the advice. So it is possible that public policies and actions could lead to harm through relying on science that happens to be wrong.

An illustration of that possibility has already been to hand for some time, though it is not often cited or noted: the sorry history of eugenics, where a fallacious expert consensus about the genetic heritability of intelligence and

1 Lorraine Daston, "When Science Went Modern," Hedgehog Review 18, no. 3 (Fall 2016): 18-32.

Henry H. Bauer is Dean Emeritus of Arts \& Sciences, Professor Emeritus of Chemistry \& Science Studies, Virginia Polytechnic Institute \& State University; hhbauer@vt.edu. 
undesirable behavioral traits led to some 70,000 Americans being forcibly sterilized during the twentieth century, including as recently as 1981.

A possible safeguard against such damaging blunders might be for policymakers to be alert to minority opinions that dissent from mainstream scientific consensus, since that is almost never entirely unanimous concerning matters relevant to public policy. But policymakers are typically unaware of any lack of unanimity among experts, or to the general fallibility of contemporary science. Nor are the media and their pundits. So it remains possible for a mistaken or misguided "scientific consensus" to stimulate public actions that are counterproductive and damaging.

Several factors make this danger to public policies a serious present-day concern. First, misunderstandings about the nature of science are many and pervasive. ${ }^{2}$ Second, it is not widely appreciated that minority views in science do not often become generally known because they are vigorously and often irrationally suppressed. ${ }^{3}$ Third, even if it is recognized that competent members of the scientific community dissent from a mainstream consensus, there is no available mechanism by which policymakers could obtain an assessment, both informed and impartial, of the relative merits of the mainstream and the minority views-those who are most closely informed are unlikely to be impartial.

After fleshing out the first two points, it will be argued that the third point might be met by the establishment of a court dedicated solely to science.

\section{Misunderstanding Science}

Science is almost universally acknowledged as authoritative for understanding the material world. Science is thought to be unbiased and objective because it employs the "scientific method." Fact-checking in science then might seem an oxymoron, as scientific statements are assumed, more or less by definition, to be based on the facts of the matter.

But this common view of science happens to be wrong. Just like every other human activity, science is performed by human beings, inevitably fallible human beings. No matter how faithfully people may try to make their actions unbiased and objective by following something like the scientific method, in

2 Henry H. Bauer, Science Is Not What You Think: How It Has Changed, Why We Can't Trust It, How It Can Be Fixed (Jefferson, NC: McFarland, 2017).

3 Henry H. Bauer, Dogmatism in Science and Medicine: How Dominant Theories Monopolize Research and Stifle the Search for Truth (Jefferson, NC: McFarland, 2012). 
practice scientists behave no more objectively or without bias than do other human beings.

That science is not done by deploying the scientific method is common knowledge in the academic realms of the history, sociology, and philosophy of science and in STS (Science \& Technology Studies), but it is rarely appreciated outside those groups. It is very rarely if ever mentioned by media pundits who interpret scientific matters for the general public.

That the popular view of science is wrong should be obvious enough once one thinks about it. Were it true, then on any given topic all scientists would have the same knowledge and understanding delivered unequivocally by the scientific method. But scientific activity exhibits pervasive differences of opinion, including some passionately bitter controversies.

But even long-standing controversies within the scientific community only matter to the general public and to policymakers when a topic is central to public policies and actions. In that case, judicious assessment of the pros and cons of opposing scientific opinions becomes of paramount importance, and it is here that fact-checking could play a significant role, to avoid something like what happened over eugenics.

The conventional wisdom is wrong about the nature of science in the twenty-first century because that wisdom is badly outdated. It is based on the characteristics that "modern" science (dated approximately from the sixteenth century) displayed during its first three centuries. It did seem as though science were then self-correcting since it progressed to increasingly better understanding of many aspects of the material world. In reality, though, this was not so much systemic self-correction as a by-product of individual self-regulation under the voluntarily shared aim of elucidating nature's secrets. Knowledge about and understanding of the natural world came from individuals of various backgrounds, talents, and interests who sometimes cooperated and sometimes competed with one another. The universally agreed criterion of success being the discovery of genuine truths about the world, such success would bring acknowledgement, approval, and acclaim from rivals, competitors, and colleagues as well as patrons. In this way, self-interested mutual regulation gave the appearance of objective self-correction.

Until the middle of the twentieth century, science could be described aptly as a cottage industry of self-driven intellectual entrepreneurs motivated 
largely by sheer curiosity, seeking reliable understanding by doing "pure" science, described in the early days as "natural philosophy."

Nowadays, however, the enormous amount of all sorts of research does not universally share the single criterion of seeking basic truths. Science nowadays is an academe-industry-government complex, a bureaucratic behemoth, with science pervasively co-opted by outside interests that pay for and thereby control the choices of research projects and the decisions of what to publish and what not to reveal publicly. These circumstances became inevitable as research grew stunningly expensive, in need of diverse supporting infrastructures. Be they private foundations, charitable foundations, government agencies, individual universities, or commercial ventures, those who fund science have their own agendas, and those are not simply truth-seeking; even what may be advertised as support for "pure science" is only provided on topics of interest to the patrons. As John Ziman noted, by the latter part of the twentieth century the traditional distinction between applied science and pure or basic science was no longer meaningful. ${ }^{4}$

Fact-checking of science is needed because "science" does not speak for itself; it is represented and presented by people and organizations that are to some extent self-interested and cannot be relied upon to self-correct. The provision of research resources is coupled with restrictions on what can be studied and on the ownership of the products of research. Nor do researchers automatically qualify for ownership of patents based on their discoveries; typically their share is negotiated in light of the restrictions and agreements drawn when support was provided. Those who pay the pipers call the tunes.

Scientific research is nowadays a white-collar profession subject to similar restraints as beset teachers, engineers, doctors. No matter how fervently idealistic individuals may be about the high overt aims of their profession, they are nevertheless beholden in significant ways to those who provide resources, and to expectations and rules prescribed for their profession by its associations, guilds, and unions. These restrictions include the usual priority to safeguard the well-being of the organization.

Successful careers are made in today's science by overcoming a variety of difficulties, only one of which is the substantive, technical work of discovering

4 John Ziman, Prometheus Bound: Science in a Dynamic Steady State (Cambridge, UK: Cambridge University Press, 1994). 
truth about how the world works. At any rate, science cannot be counted upon to self-regulate or self-correct.

To make plain for policymakers and the general public the merits of any contemporary scientific consensus that is being seriously questioned, an unbiased authority is needed to assess those merits. That is best done by observing and questioning competing arguments and opposing viewpoints and their corresponding selections of evidence and interpretation. That is how the system of civil justice functions: opposing sides argue and cross-examine in disciplined fashion under the management of unbiased individuals who have no stake in the outcome other than that it should accord as well as possible with the evident facts.

The same sort of arrangement is needed to clarify technical assertions pertinent to public policies, whenever there is serious disagreement among the technical experts. In other words, what's needed is a "Science Court" specifically dedicated to questions of science; the civil courts are simply not competent to adjudicate technical disagreements, for instance on the accrediting of expert witnesses.

\section{Dissent Opposed Vigorously}

Impartial adjudication is needed because proponents of a mainstream consensus do not engage in open argument with the maverick scientists who press unorthodox interpretations of the evidence.

Media pundits often assert a scientific consensus to be "settled science" when it seems agreed to by most or almost all professional journals as well as the National Academy, its National Research Council, the Centers for Disease Control and Prevention, the Food and Drug Administration, the National Institutes of Health, the World Health Organization, and the like. When dissenters provide facts and logic in opposition to accepted beliefs, the mainstream refuses to engage in argument; it questions the reality or the significance of those claimed facts, describing them as not genuine facts but mere random outliers or chance anomalies if not outright mistakes.

The individuals who claim that their consensus-discordant facts are real and genuine, that therefore the long-accepted mainstream belief needs to be modified, are often described as cranks or crackpots, dismissed as less than competent and perhaps not even well-intentioned, and their scientific careers are typically blemished and hindered. 
Even highly distinguished scientists may be accused of perpetrating pseudoscience when they promote claims that transgress the mainstream consensus. ${ }^{5}$ Linus Pauling, often described as the outstanding chemist of the twentieth century, was maligned for advocating the health benefits of much larger intakes of vitamins than the official RDAs (Recommended Daily Allowances). Peter Duesberg, elected at an unusually young age to the National Academy as a ground-breaking cancer researcher, was effectively excommunicated for pointing out that HIV could not cause AIDS. Nobelist Kary Mullis, inventor of the Polymerase Chain Reaction (PCR) the use of which now underlies all studies of DNA and RNA, was maligned for the similar heresy of pointing to the absence of proof that HIV causes AIDS. The highly respected electrochemist Martin Fleischmann was sent beyond the pale for claiming to have evidence of nuclear reactions at ordinary temperatures. Nobelist Luc Montagnier is laughed at for giving credence to indications of a possible efficacy of drugs at homeopathic-level dilutions. Roger Pielke withdrew from publishing about climate change because he had been so viciously harassed for skepticism as to the role of carbon dioxide. ${ }^{6}$ And this is far from an exhaustive list.

That minority views in the scientific community are given no shrift, that they are automatically dismissed, runs counter to the popular view of how science works; but it underscores what the popular wisdom also typically neglects, namely, that scientists are human, sharing the psychological weaknesses of other human beings. ${ }^{7}$ Sadly overlooked in public punditry about matters of science is the iconic article, "Resistance by scientists to scientific discovery."8

It is perfectly normal for human beings to give short shrift to evidence and assertions that run counter to their beliefs. Once a belief has been established, be it on the basis of evidence and long consideration or by accepting what parents, teachers, or other authorities taught, it becomes increasingly difficult to modify that belief. Psychologists have called the uncomfortable state of holding inconsistent thoughts, beliefs, or attitudes cognitive dissonance. Avoiding cognitive dissonance, then, is a psychological mechanism for maintaining dogmatically an acquired belief. There is also a social impetus for doing so, the

5 Babette Bakich, "Calling science pseudoscience: Fleck's Archaeologies of Fact and Latour's 'Biography of an Investigation' in AIDS denialism and homeopathy," International Studies in the Philosophy of Science 29, no. 1 (2015): 1-39.

6 Roger Pielke, "My unhappy life as a climate heretic," Wall Street Journal, December 2, 2016.

7 How this effects science is explicated for instance in Stuart Ritchie, Science Fictions: How Fraud, Bias, Negligence, and Hype Undermine the Search for Truth (Henry Holt \& Company, 2020).

8 Bernard Barber, "Resistance by scientists to scientific discovery," Science 134 (1956): 596-602. 
phenomenon of "groupthink." Every member of a group feels to some degree the importance of remaining a member of that group, and therefore tends to suppress personal doubts about the validity of the group's consensual views.

It should not be surprising, therefore, even though it runs counter to popular shibboleths about science, that distinctly dogmatic adherence to mainstream theories is normal in science, with an associated denigration of and antagonism towards mavericks who urge attention to anomalies as possibly calling for modifications of accepted theories. Examples of hidebound dogmatism that can seem irrational in the light of well attested evidence have been described on a wide range of issues: why the dinosaurs died out; the dangers of second-hand smoke; the mechanism of the sense of smell; the utility of string theory in physics; the ability of continental-drift (global-tectonics) theory to explain all salient geological phenomena; the cause of Alzheimer's disease, and of schizophrenia, and the efficacy and specificity of anti-depressant drugs; the dismissal of evidence for nuclear reactions at ordinary temperature; the insistence that the Clovis culture represents the first human settlement of the Americas.

An important caveat to what follows: despite the examples just cited, those who claim that the mainstream view on a given topic is demonstrably wrong are themselves often mistaken. The mainstream consensus is usually the most reliable guide. Dissenting heretics, typically compared to Galileo, are likely to turn out to have been wrong to some degree, perhaps even entirely. Modern-day would-be "Galileos" are not usually true prophets.

But sometimes they may be, as history teaches unequivocally. And when that happens to be the case, it may be of considerable public importance. Such rare "hard cases" would make bad laws, as the saying goes. But this entails a corollary that should be equally noted: Good laws miss the rare hard cases.

Accepting automatically, thoughtlessly, whatever a current scientific consensus happens to be can bring harm in those rare "hard cases" when "science" is seriously in error and yet determines public actions-as was the case with eugenics. So when respectable dissenters from a contemporary scientific consensus present plausibly relevant evidence, policymakers ought to pay attention and seek an unbiased adjudication, an impartial assessment of the relative merits of the differing expert opinions.

9 Irving L. Janis, Victims of Groupthink: A Psychological Study of Foreign-Policy Decisions and Fiascoes (Boston: Houghton Mifflin, 1972). 
The problem of assessing the genuine respective merits of a mainstream consensus and of claimed alternatives is compounded by the fact that, increasingly in recent decades, mainstream and dissident views have tended to become aligned with political ideology, each side claiming that the authority of science is on its side. ${ }^{10}$ Something like that blurring of technical arguments with political views was seen soon after WWII, for instance, when politically-left-leaning Robert Oppenheimer argued the technical impossibility of hydrogen bombs while politically-right-leaning Edward Teller insisted that such bombs were technically feasible. In 2020, opinions about the nature of the Covid19 pandemic and how to cope with it saw a similar split along political lines.

\section{Toward Impartial Assessments-a Science Court?}

The problem is that the most knowledgeable experts already hold firm but differing views. How to attain genuine impartiality as well as the needed technical insight?

That dilemma was discussed already more than half-a-century ago: could civilian society's necessary power generation be provided safely by nuclear (or atomic) reactors?

Policymakers were faced with the dilemma that some technical experts believed the probability of a dangerous accident to be so low that it could be ignored for all practical purposes, while other equally qualified and distinguished experts voiced the opposite opinion. Arthur Kantrowitz suggested in 1967 that society needed something like an "Institution for Scientific Judgment" whose sole purpose would be to consider carefully the technical bases of the opinions being voiced by the opposing experts. ${ }^{11}$ That concept has been discussed on a number of occasions since then, and it soon became talked of as a Science Court. Some legal scholars have pointed out that such a Court could also be of distinct and continuing value to the legal system as a whole, ${ }^{12}$ which is presently not well equipped to handle questions of scientific fact and scientific expertise.

The need for something like a Science Court is even greater now than when the idea was first broached, as scientific advice and the associated authority are

10 David Randall, "Politicized science," Academic Questions 32, no. 2 (2019): 215-222.

11 Arthur Kantrowitz, "Proposal for an Institution for Scientific Judgment," Science 156 (1967): 763-764.

12 Andrew W. Jurs, "Science Court: Past proposals, current considerations, and a suggested structure," Drake University Legal Studies Research Paper Series, Research Paper no. 11-06 (2010); reprinted in Virginia Journal of Law and Technology 15, no. 1 (Spring 2010): 1-43. 
nowadays being sought on an increasing number of matters by an increasing range and variety of sectors of society whose actions can significantly affect national and international affairs: governments and their agencies, global commercial enterprises, charitable and non-profit organizations .

There are formidable practical problems in establishing a Science Court. For instance: how to support it while allowing it the needed absolute independence? That the problems can be resolved, at least in principle, is suggested by the existence of such publicly funded yet independent and largely successful institutions as the United States Supreme Court, the Government Accountability Office, and the positions of Inspector-General in a number of federal government agencies.

\section{Contemporary Topics for the Science Court}

The generalizations and historical examples mentioned so far are largely uncontroversial, at least for academic scholars in pertinent specialties. Few would dispute that science-contemporary science, above all-is fallible, and that maverick scientists and their claims have not been taken seriously even when they later turned out to have presaged genuine progress. Those factors contribute to the present situation in which public policies on very important matters are at the mercy of scientific-technological elites.

Highly controversial, however, are the two contemporary topics which I believe illustrate instances of elite scientific consensus setting the policy agenda that rests on questionable scientific foundations. They match the unhappy precedent set by the theory of eugenics, and underscore the potential utility of unbiased adjudication by something like a Science Court.

I suggest:

1. Public policies and actions over HIV and AIDS are based on beliefs that are clearly contrary to the rather plain facts.

2. Proposed actions over purportedly human-caused climate-change are not warranted by facts long acknowledged in the scientific literature.

Carbon dioxide causes climate change and HIV causes AIDS are almost universally accepted. They represent the contemporary expert (majority) consensus, which-as acknowledged earlier-has usually turned out to be trustworthy.

But the contention here is that "HIV causes AIDS" and "carbon dioxide results in climate change" are instances of the rare "hard case" where the 
mainstream scientific consensus is flawed. The problem in calling for a Science Court is that at present, the only alternative to trusting the established authorities is to attempt to assess the evidence for oneself, something most of us cannot do.

\section{HIV and AIDS}

I hadn't reached any firm belief about whether HIV caused AIDS until the early 2000s when in the course of my research I came across dissident writers who claimed this was not true. A dive into the primary sources on the topic revealed that HIV tests do not identify sexually transmitted infection. ${ }^{13}$ The data in those primary sources left me incredulous, as their implications became increasingly unavoidable. By now, mountains of evidence have accumulated indicating that HIV is not the cause of AIDS, ${ }^{14}$ yet these facts continue to be ignored by the scientific community as a whole as well as by the HIV/ AIDS-research community, whose members refuse to engage in discussion with dissenters, including some distinguished scientists. A Science Court could force engagement over the facts and bring to public attention the following points:

1. There exists no peer-reviewed published research proving that HIV causes AIDS.

2. Pure authentic virions of HIV have never been isolated direct from anyone suffering from AIDS, or indeed from anyone testing "HIV-positive” on antibody or PCR tests.

3. The conundrum of many reported instances of HIV-negative AIDS patients was wished away in the early 1990s by declaring this a disease separate from AIDS, namely "idiopathic CD4+ T-cell lymphocytopenia (ICL).”

4. Some unknown but significant proportion of "HIV-positive” individuals have lived decades-long healthy lives while eschewing the "antiretroviral" drugs which are all significantly toxic.

A wrong theory, in this case HIV causes AIDS, can continue to preoccupy a sizable research community for decades if funding is available, as it has beenlavishly-for HIV/AIDS, from governmental sources, private foundations, and

13 Henry H. Bauer, The Origin, Persistence and Failings of HIV/AIDS Theory (Jefferson, NC: McFarland, 2007).

14 More than 900 articles and more than a dozen full-length books are cited at The Case against HIV, http:// thecaseagainsthiv.net. 
charity groups, but also from industry, as pharmaceutical companies profit handsomely from sales of antiretroviral drugs. Moreover, because the theory is wrong innumerable puzzling conundrums that justify, indeed demand further research constantly crop up.

\section{Climate Change}

The belief in human-caused climate change and global warming (AGW, for anthropogenic global warming) is widespread and attributable in part to the virtually automatic acceptance of what elite scientific authorities say, as well as to an unwarranted confidence in the power of computing to model the real world accurately. Little detailed thought is needed to recognize how unwarranted the latter belief is. The number of variables that affect weather and climate is immense, and the numbers of interactions among them are doubly immense. A climate model needs to keep track of the amounts and movements of many substances, and of several kinds of energy, in three dimensions, even as everything changes continually. Moreover, everything interacts with everything else, with positive and negative feedbacks, and those interactions are far from precisely understood. Such modeling is far beyond the capabilities of any conceivable array of even the most "super" computers. ${ }^{15}$

The only possible test of the validity of any computer model is how well it mimics actual observations. None of the models in current use have been able to represent accurately the variations of global temperature over any appreciable length of time, or for that matter any other characteristics of climate-droughts in specific regions, say, or hurricanes.

The period pertinent to present public concerns is from the middle of the nineteenth century, when the Industrial Revolution set off the eventually widespread burning of coal (and then oil and gas) that brings increasing amounts of carbon dioxide into the atmosphere.

As it happens, however, global temperatures had already been warming for some time before the Industrial Revolution. ${ }^{16}$ There was actually some cooling from about 1880 to about 1920, then warming again into the 1940s, then cooling again into the 1970s, with warming again after that. That succession of cooling

15 Orrin H. Pilkey, Linda Pilkey-Jarvis, Useless Arithmetic: Why Environmental Scientists Can't Predict the Future (New York: Columbia University Press, 2007).

16 Henry Bauer, "Climate-change facts: Temperature is not determined by carbon dioxide,"Skepticism about Science and Medicine website, May 2, 2017, https://scimedskeptic.wordpress.com/2017/05/02/ climate-change-facts-temperature-is-not-determined-by-carbon-dioxide; Don Easterbrook, "Global warming and $\mathrm{CO}_{2}$ during the past century," http://myweb.wwu.edu/dbunny/pdfs/CO2_past-century.pdf. 
and warming while carbon dioxide increased steadily should in itself demonstrate that carbon dioxide cannot be the primary cause of global temperatures. Further, it means that essentially only the period since the 1970s is available for testing models that deal with increases of temperature caused by carbon dioxide. But that then begs the question as to why temperatures have not risen appreciably in the last couple of decades.

Proponents of AGW, faithfully parroted by the mass media, have continued to say every year that global temperature is "the highest yet recorded." That misleads without actually lying: temperatures have remained essentially on a plateau since the turn of the century. The world's two leading scientific authorities, the National Academy of Sciences of the United States and the Royal Society of London, admit that there has not been appreciable global warming during that time, though they attempt to dismiss this as a relatively short, anomalous pause. ${ }^{17}$

The most salient empirical fact, which would be brought to the attention of a Science Court by a public hearing, is that the Earth's history demonstrates that atmospheric carbon dioxide is not consistently correlated with global temperature. The long-standing research literature in geology records that temperatures have sometimes been high when levels of atmospheric carbon dioxide were low, and vice versa. ${ }^{18}$ Moreover, the last million years have seen seven or eight Ice Ages separated by warm periods, with maximum differences between cold and warm about five or six degrees Centigrade; which makes a mockery, incidentally, of the supposed need, frequently asserted by activists, to prevent global warming of more than two degrees.

But these facts are not cited by the media or its pundits, and the critics of AGW are ignored or maligned.

\section{Conclusion}

The status of science as supreme arbiter of true temporal knowledge, together with significant misunderstanding about science, has brought public actions based on misguided advice from scientific authorities. It needs to be

17 Climate Change: Evidence \& Causes-An overview from the Royal Society and the U.S National Academy of Sciences (Washington, DC: National Academies Press, 2014). For a detailed critique, see Henry H. Bauer, "Climate-change science or climate-change propaganda?," Journal of Scientific Exploration 29 (2015): 621-636.

18 "Climate-change facts: Temperature is not determined by carbon dioxide," May 2, 2017, https://scimedskeptic.wordpress.com/2017/05/02/climate-change-facts-temperature-is-not-determined-by-carbon-dioxide; Don Easterbrook, "Global warming and CO2 during the past century," http://myweb.wwu. edu/dbunny/pdfs/CO2_past-century.pdf. 
recognized that "science" is not synonymous with what scientists say or believe, and that statements from scientific experts warrant as much skepticism as statements from other experts, influenced as they inevitably are by personal, institutional, and traditional biases, self-interest, and groupthink.

On matters of public importance, "science" needs to be fact-checked and adjudicated by a Science Court. 